\title{
A New Report of Odontosia sieversii (Lepidoptera: Notodontidae) from Korea
}

\author{
Sei-Woong Choi ${ }^{1, *}$, Sung-Soo Kim² \\ ${ }^{1}$ Department of Environmental Education, Mokpo National University, Muan 530-729, Korea \\ ${ }^{2}$ Research Institute for East Asian Environment and Biology, Seoul 134-053, Korea
}

\begin{abstract}
In Korea, 104 species of Notodontidae have been recorded. The genus Odontosia Hübner is characterized by the elongate and serrate margin of its forewing and the prominent harpe of valva and many spinular cornuti on the vesica of the male genitalia and the robust ductus bursae and large, ovate and sclerotized corpus bursae of the female genitalia. Only one species of Odontosia, O. patricia Stichel, 1918, has been reported from Korea. In this paper, Odontosia sieversii (Ménétriès, 1856) is newly added to the Korean fauna based on three male specimens collected at Mt. Bangtaesan, Gangwon-do, Korea. Diagnosis for the species and photographs of adult and genitalia of the genus Odontosia are provided.
\end{abstract}

Keywords: Odontosia, Odontosia patricia, Odontosia sieversii, Notodontidae, Korea, new record

\section{INTRODUCTION}

Moths of Notodontidae are medium to large-sized moths, comprising approximately 2,500-3,000 species worldwide (Scoble, 1992). They can be easily recognized by the large and triangular forewing with a large prominent "tooth" on the posterior margin and long abdomen. This prominent "tooth" of the forewing produces a tuft that breaks the insect's outline and aids crypsis while the moth is at rest (Miller, 1991; Park and Kwon, 2001). The monophyly of the Notodontidae is well supported by the serrated edges on the tips of the tibial spurs and a teardrop-shaped, swollen area (bulla) of the metascutal region above the tympanum (Miller, 1991; Scoble, 1992). In larvae, two MD setae on A1, seta X in the anterolateral corner of the anal shield, one SV seta on T2 and T3, a smooth mandibular cutting edge of the late instar larvae, the dorsoventrally compressed and bifid adenosma, and the highly modified anal prolegs that often with eversible distal glands are common characteristics of notodontid larvae (Kitching and Rawlins, 1999).

In Korea, 104 species of Notodontidae have been recorded (Park and Kwon, 2011). The genus Odontosia Hübner is characterized by the violet-brownish ground color, the elongate and serrate margin of the forewing, the prominent harpe of valva and many spinular cornuti on the vesica of the male genitalia and the robust ductus bursae and the large, ovate and sclerotized corpus bursae of the female genitalia (Schintlmeister, 2008). Four species of Odontosia are recorded in the Palearctic region (Schintlmeister, 2008). One species of Odontosia, O. patricia Stichel was known in South Korea (Choi, 2008; Park and Kwon, 2011). The aim of the present study was to review the species of Odontosia in Korea, including a new record of the second species of Odontosia from Korea. Examination of adults including male genitalia refers to Scoble (1992). The specimens are preserved at Mokpo National University, Jeonnam, Korea. Abbreviations are as follows: JN, Province Jeollanam-do; GW, Province Gangwon-do; MNU, Mokpo National University.

\section{SYSTEMATIC ACCOUNTS}

Order Lepidoptera Linnaeus, 1758

Family Notodontidae, Stephens, 1829

Genus Odontosia Hübner, 1819

Odontosia Hübner, 1819: 145. Type species: Phalaena carmelita Esper, 1799.

Diagnosis. The members of the genus can be distinguished by the bipectinate male antennae, short labial palpi, vestigial (c) This is an Open Access article distributed under the terms of the Creative Commons Attribution Non-Commercial License (http://creativecommons.org/ licenses/by-nc/3.0/) which permits unrestricted non-commercial use, distribution, and reproduction in any medium, provided the original work is properly cited.

pISSN 2234-6953 eISSN 2234-8190
*To whom correspondence should be addressed

Tel: 82-61-450-2783, Fax: 82-61-450-2789

E-mail: choisw@mokpo.ac.kr 

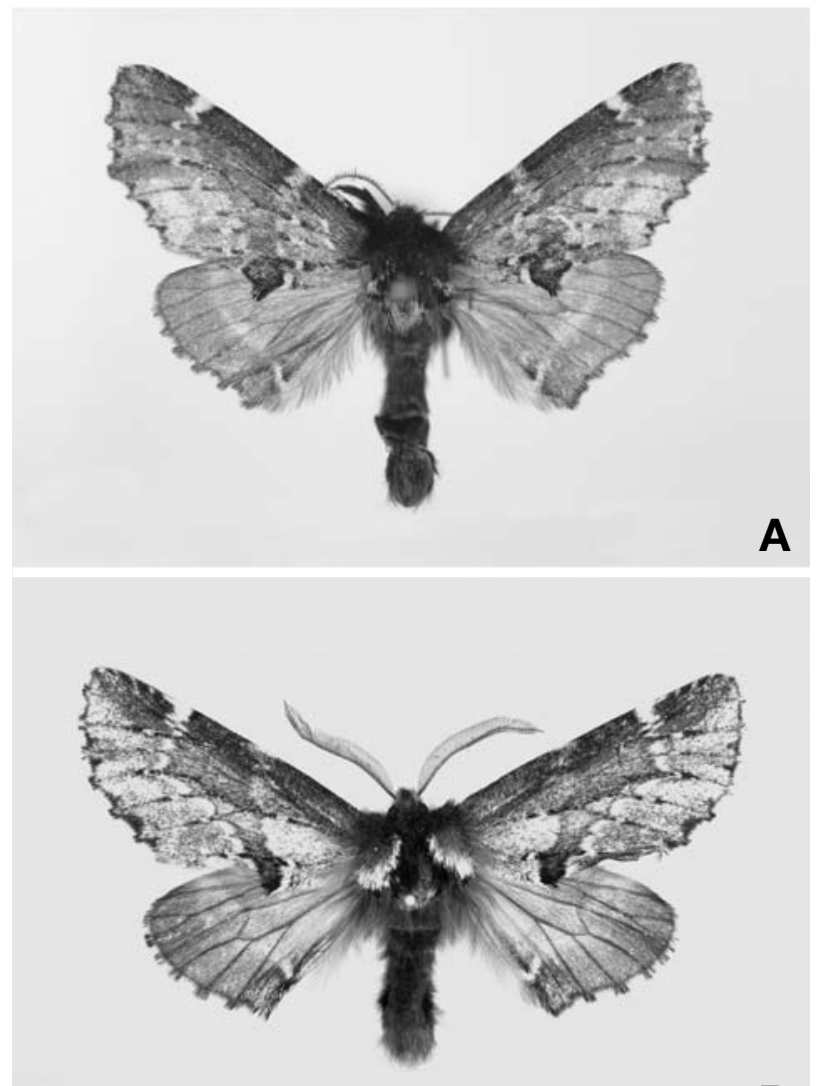

B

Fig. 1. Adults of Odontosia Hübner. A, Odontosia patricia; B, Odontosia sieversii.

proboscis, thorax with dense woolly hair and scales, and elongate wings with thinly scaled forewing with strongly serrate margin. They are similar to those of Lophontosia Staudinger in the dorsally tapering central fascia of forewing and dentate distal margin of wings. However, these two genera can be separated by the wing ground color and the male and female genitalia. The male genitalia are characterized by the relatively short and hooked uncus and a pair of digitate gnathos, a medially expanded long slender membranous valva and a sclerotized harpe and the broad, shallow saccus. The male genitalia of Odontosia can be distinguished from those of Lophontosia by the relatively long and well-developed gnathos and broad saccus without medial projection. The female genitalia can be distinguished by the simple ostium bursae, the long sclerotized ductus bursae, and the large ovate corpus bursae with a patch of signa.

\section{Odontosia patricia Stichel (Korean name:}

Top-ni-tti-jae-ju-na-bang) (Figs. 1A, 2A, B)

Odontosia patricia Stichel, 1918: 38, Pl. 1:20 (TL: Vladivo-
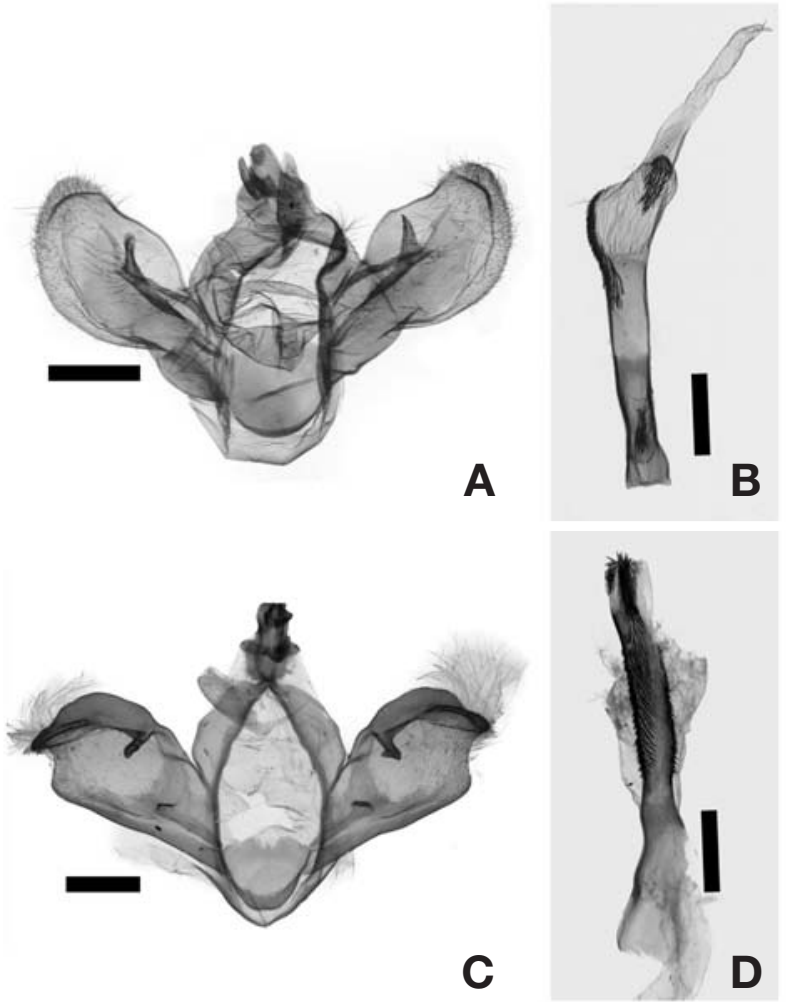

Fig. 2. Male genitalia of Odontosia Hübner. A, B, Odontosia patricia; C, D, Odontosia sieversii. Scale bars: $A-D=1 \mathrm{~mm}$.

stok).

Odontosia walakui Kobayashi, 2006: 155 (TL: Japan, Hokkaido); Schintlmeister, 2008: 317.

Odontosia brinikhi Dubatolov, 2006: 157 (cited from Kobayashi et al., 2006); Schintlmeister, 2008: 317.

Material examined. Korea: [JN], $2 \sigma^{\top}$, Gurye, Jirisan Mt., $\mathrm{N} 35^{\circ} 18^{\prime} 02^{\prime \prime}, \mathrm{E} 127^{\circ} 33^{\prime} 10^{\prime \prime}$, 1,371 m, 22 May 2008, coll. MNU; $3 \sigma^{\nearrow}$, Gurye, Jirisan Mt., N35 $18^{\prime} 02^{\prime \prime}$, E $127^{\circ} 33^{\prime} 10^{\prime \prime}$, 1,371 m, 12 May 2008, coll. MNU; $40^{7}$, Gurye, Jirisan Mt., $\mathrm{N} 35^{\circ} 18^{\prime} 13^{\prime \prime}, \mathrm{E} 127^{\circ} 33^{\prime} 35^{\prime \prime}$, 1,330 m, 12 May 2012, coll.

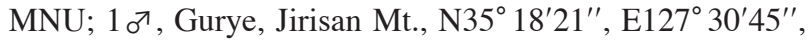
1,074 m, 11 May 2012, coll. MNU.

Diagnosis. This species (wingspan 35-38 mm) can be distinguished by the larger wingspan, the shortly bipectinate male antennae, short labial palpi, long and brown hairy thorax and legs, and the dorsally shrunk central fascia with dentate postmedial line of dark brownish forewing. This species is externally similar to $O$. sieversii (Ménétriès) in the shape of wings, but can be distinguished by the short bipectinate male antennae, the darker, blackish wing ground color and the costally projected yellowish white postmedial lines of forewings. The male genitalia (Fig. 2A, B) can be diagnosed by the relatively 
short and hooked uncus, a pair of digitate gnathos, the slender membranous valva with dorsally expanded and a long, strongly sclerotized digitate harpe and slender aedeagus with three patches of spinular cornuti. The male genitalia of $O$. patricia can be distinguished from those of $O$. sieversii by the less developed costa, the larger cucullus with rounded distal margin and the relatively long and spinular harpe of valva. The female genitalia of $O$. patricia are characterized by the simple ostium bursae, the medially expanded and strongly sclerotized ductus bursae and the ovate corpus bursae with a rounded signum patch of spinular processes (Schintlmeister, 2008).

Biology. The species feeds on Betula (Betulaceae) (Nishio, 2004).

Distribution. Korea, Japan, Russia (Siberia west, Mt. Sajan, Primorye), Mongolia.

Odontosia sieversii (Ménétriès, 1856) (Korean name: Bom-jae-ju-na-bang) (Figs. 1B, 2C, D)

Notodonta sieversii Ménétriès, 1856: 44 (TL: Russia, St. Petersburg).

Odontosia sieversii ussurica Bytinski-Salz, 1939: 167 (TL: Russia, Primorye).

Odontosia seversii moravia Daniel, 1964: 39, Pl. 6: 8-11

(TL: Czechia); Schintlmeister, 2008: 319.

Odontosia arnoldiana Kiriakoff, 1967: 187 (TL: Russia, Wladiwostok); Schintlmeister, 2008: 319.

Odontosia sieversii japonibia Matsumura, 1929: 44 (TL: Japan, Sapporo).

Material examined. Korea: 3 ð [GW], Mt. Bangtaesan, Jeongseon-gun, 17 Apr 2012, Kim SS.

Diagnosis. The species (Wingspan $40-42 \mathrm{~mm}$ ) is superficially related to $O$. patricia Stichel in the fuscous forewing and grayish hindwing and wing pattern elements of both fore and hindwings, but can be distinguished by its rather larger size, the long bipectinate male antennae, the medially more sharply pointed postmedial line and the thin and blackish marking on the dorsum of forewing, and the simple 8th sternite without the sclerotized flap. The male genitalia (Fig. 2C, D) can be characterized by the short, robust uncus, a pair of digitate socii, the broad valva, the strongly sclerotized costa with a basal spear head-shaped process and a distal spatulate process, the minute harpe, and the aedeagus with 3-4 long patches of spinules. The male genitalia of $O$. sieversii can be distinguished from those of $O$. patricia by the strongly sclerotized costa with a long basal process and a distal broad process, the short harpe and the long patches of spinules on the aedeagus. The female genitalia of $O$. sieversii are characterized by the simple, sclerotized ostium bursae, the long sclerotized ductus bursae and the small ovate corpus bursae (Schintlmeister, 2008). The female genitalia of $O$. sieversii can be distinguished from those of $O$. patricia by the long, slender ductus bursae and the membranous corpus bursae with a signum patch.

Biology. This species appears in April. The species feeds on Betula (Betulaceae) (Sugi, 1987).

Distribution. Korea (new record), Japan to Europe.

Remarks. Schintlmeister (2008) noted the presence of this species in Korea without any detailed information. He included Heilongjiang of northeastern China and Russian Far East in the distribution map of this species, except the Korean peninsula. Park and Kwon (2011) did not include $O$. sieversii in the list of the Korean Notodontidae. Therefore, we proposed that this is the first time to report the presence of $O$. sieversii in Korea.

\section{ACKNOWLEDGMENTS}

This study was supported by a grant from the National Institute of Biological Resources (NIBR), funded by the Ministry of Environment (MOE) of the Republic of Korea (NIBR No. 2013-02-001).

\section{REFERENCES}

Bytinski-Salz H, 1939. New species and forms of palaearctic Bombycine moths. Entomologist's Record and Journal of Variation, 51:165-167.

Choi SW, 2008. Odontosia particia (Lepidoptera: Notodontidae) new to Korea, with comment on the notodontid fauna of high altitude of Jirisan Mt. Korean Journal of Systematic Zoology, 24:269-272.

Daniel F, 1964. Odontosia sieversi Mén. und patricia Stich. (Lep.Notodontidae). Zeitschrift der Wiener Entomologischen Gesellschaft, 49:37-47.

Hübner J, 1819. Verzeichniss bekannter Schmettlinge. Vol. 10. Bey dem Verfasser zu Finden, Augsburg, p. 145.

Kiriakoff SG, 1967. Lepidoptera Familia Notodontidae Pars secunda Genera Palaearctica. In: Genera Insectorum Fasc. (Ed., Wystman P). Kraainem, pp. 1-238.

Kitching IJ, Rawlins JE, 1999. The Noctuoidea. In: Lepidoptera, moths and butterflies. Vol. 1. Evolution, systematics and biogeography (Ed., Kristensen NP). Walter de Gruyter, Berlin, pp. 355-401.

Kobayashi H, Dubatolov V, Kishida Y, 2006. A review of the Odontosia Carmelita-patricia species group (Lepidoptera, Notodontidae), with descriptions of two new species from Russia and Japan. Tinea, 19:154-164.

Matsumura S, 1929. New species and genera of Notodontidae. Insecta Matsumurana, 4:36-48.

Ménétriès E, 1856. Description de deux espèces nouvelles de Lépidoptères trouvées près de St. Petersbourg. Études Ento- 
mologieques, 5:42-50.

Miller JS, 1991. Cladistics and classification of the Notodontidae (Lepidoptera: Noctuioidea) based on larval and adult morphology. Bulletin of American Museum of Natural History, 204:1-230.

Nishio N, 2004. Larva of Odontosia patricia Stichel (Notodontidae) on Betula platyphylla (Betulaceae) in Primorye region. Yugato, 178:144.

Park KT, Kwon YD, 2001. Superfamily Bombycoidea and family Notodontidae. Economic insects of Korea 7. Insecta Koreana Supplement, 14:43-147.

Park KT, Kwon YD, 2011. Prominents (Arthropoda: Insecta: Lepidoptera: Notodontidae), Insect fauna of Korea (Lepidoptera: Notodontidae), Vol. 16, No. 2. National Institute of
Biological Resources, Ministry of Envrionment, Incheon, pp. 1-246.

Schintlmeister A, 2008. Notodontidae. Palaearctic Macrolepidoptera. Vol. 1. Apollo Books, Stenstrup, pp. 1-482.

Scoble MJ, 1992. The Lepidoptera: form, function and diversity. Oxford University Press, Oxford, pp. 1-404.

Stichel H, 1918. Zur Monographie der Odontosia sieversi (Mén.) sowie Beschreibung einer neuen verwandten Art. Zeitschrift für Wissenschaftliche Insektenbiologie, 14:25-38.

Sugi S, 1987. Larvae of larger moths in Japan. Kodansha, Tokyo, pp. 1-301 (in Japanese with English summary).

Received June 20, 2013

Revised July 23, 2013

Accepted July 28, 2013 